\title{
Article \\ Transfer Capital or Transfer Deficit: A Dual Perspective of English Learning of ESL College Transfer Students
}

\author{
Dennis Foung ${ }^{1}$ and Kin Cheung ${ }^{2, *(\mathbb{D})}$ \\ 1 School of Journalism, Writing, and Media, The University of British Columbia, \\ Vancouver, BC V6T 1Z2, Canada; dennis.foung@gmail.com \\ 2 School of Nursing, The Hong Kong Polytechnic University, Hong Kong, China \\ * Correspondence: kin.cheung@polyu.edu.hk
}

check for

updates

Citation: Foung, D.; Cheung, K. Transfer Capital or Transfer Deficit: A Dual Perspective of English Learning of ESL College Transfer Students. Sustainability 2022, 14, 214. https:// doi.org/10.3390/su14010214

Academic Editors: Xuesong (Andy) Gao and Mairin Hennebry-Leung

Received: 26 October 2021

Accepted: 23 December 2021

Published: 26 December 2021

Publisher's Note: MDPI stays neutral with regard to jurisdictional claims in published maps and institutional affiliations.

Copyright: (c) 2021 by the authors. Licensee MDPI, Basel, Switzerland. This article is an open access article distributed under the terms and conditions of the Creative Commons Attribution (CC BY) license (https:// creativecommons.org/licenses/by/ $4.0 /)$.

\begin{abstract}
This research addressed a research gap in scrutinizing the language problems of English as a second language (ESL) transfer students (TSs) with regard to the aspects of "transfer deficit" and "transfer capital", instead of simply labelling the use of English as a "transfer deficit". One hundred and twenty-four TSs participated in this qualitative study. From qualitative content analysis, three main categories were identified: (a) English competence as transfer capital; (b) English competence as transfer deficit; and (c) transition from deficit to capital. Based on the results, educational practitioners are advised to pay attention to the specific implications of proficiency-based courses, with support measures not limited to essay-writing or referencing skills, but including advanced research writing genres such as the Capstone Project.
\end{abstract}

Keywords: transfer capital; transfer deficit; transfer students; associate degree; higher diploma; academic performance

\section{Introduction}

Community colleges provide opportunities as "stepping stones" to higher education [1] for students to transfer from two-year community college to four-year university studies. College transfer students (TSs) are those who have completed a two-year postsecondary qualification and are admitted to a four-year university program [2-5]. Although this pathway offers students another chance to earn bachelor's degrees at university, thus promoting educational equality and democratization in society [6,7], there is a problematic issue of "transfer shock", which was first described by Hills [8]. Later studies have described these issues as "transfer capital" [9] or "transfer deficits" [10] in their attempts to present these issues as long-term assets or burdens to TSs.

This paper focuses on college TSs in Hong Kong, where around 30\% of community college students are eligible to be admitted to the university as vertical TSs (Table 1a,b). For most college TSs, English is the second language ("ESL"), with Chinese being their first language. In particular, this paper aims to examine how the English competence of these TSs can be "transfer capital" or a "transfer deficit". 
Table 1. (a) No. of community college graduates in Hong Kong; (b) No. of publicly funded undergraduate programs for vertical TSs in Hong Kong.

\begin{tabular}{|c|c|c|c|}
\hline \multicolumn{4}{|c|}{ (a) } \\
\hline Graduates for & $16 / 17$ & $17 / 18$ & $18 / 19$ \\
\hline higher diploma & 6986 & 6382 & 5619 \\
\hline associate degree & 8246 & 8460 & 8334 \\
\hline TOTAL & 15,232 & 14,842 & 13,953 \\
\hline \multicolumn{4}{|c|}{ (b) } \\
\hline College transfer-intake for & $17 / 18$ & $18 / 19$ & $19 / 20$ \\
\hline publicly funded places & 4900 & 5000 & 5100 \\
\hline * Transfer rate & $32.17 \%$ & $33.69 \%$ & $36.56 \%$ \\
\hline
\end{tabular}

One noteworthy issue is that community college students in Hong Kong follow this route to university mainly because of their public examination scores and not because of demographic factors. Students who obtain higher scores in secondary school exit examinations are admitted directly to university, while those with relatively lower scores have to complete post-secondary qualifications before being admitted as a second chance $[6,13]$. This distinct background warrants examining the process of college transfer as one of the common problems faced by these TSs.

\subsection{Transfer Shock}

There has been a considerable amount of research investigating the transition process of college TSs, with most of this having been conducted in the United States. One issue to have emerged from this research is the aforementioned "transfer shock", first described by Hills [8]. Transfer shock is characterized by TSs experiencing a drop in their GPAs in the first semester after entering university. This shock could be due to the fact that they need to deal with a great number of transition problems. One is being thrown into an environment of new peers and/or grading mechanisms, which can result in lower grades and other challenges. However, the concept of "transfer shock" can be interpreted in different ways. Some authors have suggested that it may in fact be a consequence of the two-year college studies, such as poor academic preparation [14] and other factors including social isolation and credit loss [15]. Others have claimed that the problem is generated in the university, such as relationships with new students [16] and insufficient (or even confusing) support provided by the university [17]. Due to the brevity of this paper, a more in-depth discussion of the transfer shock of college TSs is not included here, but can be obtained from the authors of [3], Wong [6], and Cameron [18].

\subsection{Transfer Capital and Transfer Deficit}

In general, there are two main approaches to scrutinizing the problems of the transfer process. Generally, previous research has suggested that "transfer shock" is a temporary issue during the transfer process, and technically, these issues/shocks can be solved easily (e.g., providing timely information in TS orientation). As "transfer shock" is regarded as temporary, other researchers have attempted to understand its prolonged effect on students during the transfer process. In what follows, we can see how scholars in recent decades attempted to look at "transfer capital" ("TC") [9] and "transfer deficit" ("TD") [10] with issues that last for longer/have a long-term impact (e.g., skills that have (not) been learned during sub-degree studies).

"Transfer deficit", as identified by McCormick, Sarraf, Brcka, Lorenz, and Haywood [9], refers to the problems facing TSs after they have entered university. This team found that student-faculty relationships (at university) and the advice available for students are factors that can affect TD. The term "transfer capital", as introduced by Laanan, Starobin, 
and Eggleston [10], conceptualizes the knowledge that TSs have developed to facilitate the transfer process, for example, note-taking skills, problem-solving skills, and timemanagement skills. Their study also reported that TSs who have gained these soft skills through their study in their community colleges "move beyond the transfer shock" with better college transfer experiences. With the introduction of the "capital" and "deficit" concept, the discussion of the college transfer process becomes richer, as it allows further discussion of the factors contributing to the success or failure of the process.

\subsection{English Competence}

English competence is one of a number of factors that can contribute to "transfer shock", but it seems to be one of the most common, especially for ESL students who have trouble with their academic performances because of their language abilities $[19,20]$. These troubles can contribute to other negative impacts on the psychological process of the transition [21]. While there is not a great deal of research about this issue in the university context, some studies have addressed "transfer deficit" by examining the whole transfer system. Pullen [22], for example, found that his ESL students took one or two semesters to prepare themselves for source-based writing in university because of poor foundations in their secondary education. Thus, their lack of English proficiency was a "deficit" that led to other learning difficulties. Similarly, Frodesen [23] concluded with a list of needs (i.e., deficits) for international TSs, from writing some specific assignment genres (e.g., summarizing) to the development of writing strategies (e.g., revising) and vocabulary enhancement. According to Castro and Cortez [24], it is not only the ESL students' actual English performances that cause deficits, but also their perceptions of their abilities. For example, Mexican ESL TSs in their study believed that they just did not have the language proficiency needed for four-year university courses. Others found that some ESL students were disadvantaged simply because of poor academic advice and not knowing which remedial English courses to take [17].

Despite the evidence supporting the role of "deficits", many studies have not paid them sufficient attention. Schwehm [25], for example, believed that TSs should be fine as long as they all complete their needed remedial classes, including English. Little information has been given about the kinds of remediation needed. Moreover, few studies have discussed English ability as a TC. For example, Robison, Fawley, and Marshall [17] identified TSs' abilities to look for sources as an example of "transfer capital". However, they had another view defining this "capital" under the scope of library skills, instead of academic literacy in general. Other than this, not many studies have identified language-related "transfer capital" thoroughly, and appear to have undermined the value of English courses offered in colleges.

Due to the lack of a comprehensive account of both TD and TC, the following research questions were posed:

1. To what extent is English competence a TD for ESL college TSs?

2. Can English competence and other language-related factors be TCs for ESL college TSs?

\section{Materials and Methods}

\subsection{Design}

In this study, focus group interviews were used for the data collection [26]. The advantage of the focus group is its interactive nature, which encourages the participants to manifest their thoughts as a certain subject discussion unfolds [27]. The purpose was to invite the participants to participate in a debate rather than to look for reaching a consensus among them [28]. This procedure can be used to obtain a comprehensive and thorough understanding of the content [29]. 


\subsection{Participants}

In this qualitative research, purposive sampling was adopted to recruit college TSs in Hong Kong. Four selection criteria were used to select college TSs who:

i. Had graduated from a two-year community college program and were studying in bachelor programs in various fields of study;

ii. Had been studying in the program for at least one semester;

iii. Were of Chinese ethnicity; and

iv. Used English as a second language (ESL; that is their mother tongue was Chinese and they used Chinese in their daily lives but used English mainly in academic contexts).

The invitation was issued by emails sent to all of the current college TSs studying either year-one, -two, or -three bachelor programs. (There was only one health-related program with three years of study.) Through email correspondence, the students who agreed to participate were invited to participate in the focus group at the designated research site.

\subsection{Data Collection}

The aim of the focus group interviews was to collect a range of experiences and perspectives [30]. The group sessions were semi-structured and moderated by an interviewer in an informal setting [31].

From February 2018 to March 2019, 39 focus groups and 7 individual interviews were conducted. A total of 124 current college TSs were invited to participate in the study. Of these, 40 were male and 84 were female, coming from all years of study (i.e., from year 1 to 3). They also came from various academic disciplines: medicine, dentistry, and health sciences (MDHS); business and management (BM); services (SV); engineering and technology (ET); languages and related studies (LRS); social sciences (SS); arts, design and performing arts (ADPA); and computer science and information technology (CSIT) [26] Depending on their availability, each group consisted of 1 to 5 participants. The duration of the interviews was approximately 30 to $45 \mathrm{~min}$. Each student was interviewed once by an interviewer with expertise in qualitative studies, as shown in the interview guide (Table 2). The interviewer was assisted by a research assistant, whose role was to record the interviews. The medium of language for all interviews was Cantonese, the participants' first language [26].

Table 2. Interview guide.

\begin{tabular}{|c|c|}
\hline \multicolumn{2}{|r|}{ General Broad Opening Question } \\
\hline 1. & $\begin{array}{c}\text { Can you tell me about your experiences in using English, until now, } \\
\text { in the university? }\end{array}$ \\
\hline \multicolumn{2}{|r|}{ Probing Questions } \\
\hline 1. & $\begin{array}{l}\text { When considering your English proficiency as a whole, which aspects are you } \\
\text { good at? Which aspects of English usage are you weak at? }\end{array}$ \\
\hline 2. & Which areas of English usage do you think you need help with? \\
\hline 3. & Have you experienced any problems in learning or using English? \\
\hline 4. & $\begin{array}{c}\text { Have you experienced any problems with studying (interviewee's discipline) } \\
\text { that were related to English? }\end{array}$ \\
\hline
\end{tabular}

The interview approach was funnel-based [30]. The interviews commenced with, "We have some questions about English use. First of all, in general, please describe your English learning experience in the university so far". The broad, yet accurate, questions encouraged the participants to express their individuality. The moderator's role [32] was to facilitate the interactions and provide "a non-threatening supportive climate" for the participants to discuss important questions [33]. Therefore, it was highly important for the interviewer 
and research assistant to have debriefing sessions after each focus group interview in order to manage the key themes and hunches that had been noted.

\subsection{Data Analysis}

The collected data were subjected to qualitative content analysis [14]. First, the recorded interviews were transcribed by the research assistant, and then the transcript was transferred to NVivo Pro 120 for easy analysis. The qualitative content analysis then began with five steps: (1) reading/re-reading the transcriptions for better immersion in the data; (2) identifying meaning units related to students' transfer shock, capital, and deficit; (3) labelling these meaning units with codes, e.g., transfer shock, capital, and deficit; (4) identifying/grouping these groups into subcategories; and (5) identifying three categories: transfer capital, transfer deficit, and in-between capital and deficit.

To ensure the quality of data analysis, the coding for the four interviews was done by the interviewer and the research assistant separately. The inter-coder reliability was checked and discrepancies were discussed and resolved. They also discussed the coding and categories before presenting the results to the entire research team.

\subsection{Ethical Considerations}

This research was approved by the research committee of the researchers' university and institutional ethical clearance was obtained (HSEARS20170808003).

\section{Results}

The aim of this study was to explore the role of ESL TSs' English competence (and other language-related factors) in TC and TD. The results section is divided into three parts: "English competence as transfer capital", "English competence as transfer deficit", and "Transition from deficit to capital" (Table 3).

Table 3. Summary of categories and subcategories.

\begin{tabular}{cc}
\hline Categories & Subcategories \\
\hline English competence as TC & (i) Basic academic skills as TC \\
English competence as TD & (i) Listening and speaking skills in non-academic \\
context as TD \\
(ii) Reading and writing in advanced research writing \\
genres as TD
\end{tabular}

\subsection{English Competence as TC}

\subsubsection{Basic Academic Skills as TC}

The college TSs perceived that their community college studies had prepared their English proficiency generally enough for them to attend classes, handle assignments, and adapt to university studies.

"For attending classes or taking notes, and all the lecturers are giving their lectures in English." (33A, SS, YR1)

"I cannot say I am good at English, but sufficient for me to handle assignments and to attend classes. Even if I do not know how to spell a word, I still have a sense of what it looks like, or I can relate the word to the topic it belongs to. It is okay for me to search for its meanings afterward." (08B, MDHS, YR1)

"I think my English is sufficient for me to handle assignments." (05B, MDHS, YR1) 


\subsubsection{General Academic Writing Skills as TC}

General academic writing skills were also identified, i.e., academic writing practices that apply to any discipline. These were mainly the organizational skills for written communication, going from macro structures of academic papers (e.g., introduction and conclusion), strategies for paragraph development (e.g., topic sentence or paragraph coherence), and incorporation of sources to academic writing styles.

"It (English learnt in community college courses) is useful for organizational structure when writing statements and papers: what should be included in the introduction, main content, and conclusion, how to write the first sentence which is the topic sentence, and how to further elaborate." (16D, LRS, YR2)

"Academic writing is useful ... (they) taught me how to cite references, how to paraphrase." (32B, ATP, YR2)

\subsubsection{Advancement of English Proficiency as TC}

Some students also described how the disciplinary words learned in community college helped them in their university studies. This included knowing discipline-specific vocabulary useful for their current academic studies and strategies for acquiring vocabulary.

"I graduated from a vocational training institution. The English I learnt was job-related ... that is English for the workplace" (06B, CSIT, YR1)

"Prefix and suffix ... Nursing students need to learn a lot of medical terms. Even if I do not understand the whole word, I can guess the meaning by the suffix of the word." (13B, MDHS, YR1)

These general academic skills, general academic writing skills, and strategies were built and developed in community college studies, and the students found them to be useful in their university studies.

\subsection{English Competence as TD}

Due to the lack of exposure to multicultural English learning environments, the students had experienced deficits in listening and speaking skills, particularly in nonacademic contexts. They had also experienced challenges with reading and advanced research writing genres.

\subsubsection{Listening and Speaking Skills in Non-Academic Context as TD}

The college TSs reported difficulties in understanding certain accents and feeling uncomfortable to talk with international students from other countries. This might be attributed to their lack of exposure to multicultural environments, as their English learning was confined to the school environment.

"I think my weakness is listening when people speak with accents or so fast that I cannot catch what they are saying ... When I try to listen to what others say, I just cannot understand." (33C, SS, YR2)

"When I am communicating with others who have accents, I cannot understand what they are talking about." (27B, BM, YR2)

"I graduated from a Chinese-medium secondary school. Most of the time, I do not speak or even use English. I can only learn English through reading and writing. Objectively speaking, my English speaking and listening are worse than other students who graduated from English-medium secondary schools." (09, MDHS, YR1)

The students indicated that they faced the dilemma of finding the right words to express themselves, or that they avoided expressing themselves at all. This generally did not affect their understanding of lectures or communication during tutorials. Yet, some were of the view that this could be a problem when teachers speak quickly. 
"Speaking in English... I am not confident to speak English, or I dare not speak in a sentence because I am not sure I am speaking in a correct way." (11A, ET, YR2)

"I think speaking in English is the most difficult part. This is because I do not know how to express myself in English. In some cases, the worst scenario is that even if I really want to say something, I just cannot say it ... or another scenario is that I am afraid to speak in English because I am simply scared. On the one hand, I cannot speak fluently, and on the other hand, I am afraid I am speaking with an unpleasant accent." (33B, SS, YR2)

"Sometimes when the teacher speaks a bit faster, I cannot comprehend immediately. I have to think about what the teacher said in Chinese first, because I have got used to taking notes in Chinese. If the teacher is using English as the teaching medium, I need some time to think about what the teacher said. However, when I finally get what the teacher said, he or she has already moved on, and I feel like I have missed something." (07D, MDHS, YR2)

Further, when the students studied with international students, they felt terrible when they realized that they could not be understood by the international students.

"I joined a study group with students from other countries, such as Switzerland and Australia. There was a tutorial for us to exchange views on the nursing practices in different countries. This was done in English. When I tried to speak English, I had a lot of fillers in my sentences. I felt terrible, especially when no one could understand what I was talking about." (01A, MDHS, YR2)

Whenever it was possible to use Chinese for communication, the students tended to do so. Even in situations where their teachers asked questions in English, the students might still respond in Chinese.

"I think an English learning environment is very important. This is because most of our classmates are speaking Cantonese as their first language ... When the teachers ask us questions in English, we will choose to use Chinese to respond." (19E, MDHS, YR3)

\subsubsection{Reading and Writing in Advanced Research Writing Genres as TD}

The students said that they faced challenges in reading research papers because of unfamiliar vocabulary and structure.

"I think it is difficult to understand the phrases and vocabulary when reading articles in English. These are the words you cannot comprehend by just checking the dictionary. The whole structure and sentence structure are difficult to understand." (04B, MDHS, YR2)

The students also reported that they had not acquired the skills of reading literature efficiently and systematically for the journal articles they sought to understand.

"Research skills are also important to us, because we have to read a lot of medical journals." "We do not know the reading skills for reading research journal articles. Without understanding these types of articles, it is difficult to study." (13B, MDHS, YR1)

"I think the literature review is important. It may be because we are required to read a lot of literature, for writing papers, but we read it slowly or we cannot understand it. This is the aspect we need to improve, our reading efficiency." (33C, SS, YR2)

In addition, the students faced a challenge when writing academic papers with the "micro" writing process, i.e., presenting ideas in sentences in English. Their proficiency also concerned them, i.e., accuracy, grammar, and variety in sentence structure and vocabulary. 
"I would say (my major challenges would be) writing academic papers like how to write the papers better. Basically, every course requires us to write a term paper. I feel like dying when I am asked to write academic papers. This is because, at some point, we know how to express ideas in Chinese but not in English. In some cases, we might just write too much, to the extent that others do not understand. Or, in some other cases, I will just keep it short, to include only the keywords, as I cannot think of a way to further elaborate it. I think the crux of the problem is that even if we can think of how well we can write about certain ideas, we just cannot present these ideas in English." (33B, SS, YR2, female)

"When writing, sometimes I do not know how to express my ideas in English." (14A, MDHS, YR1)

"It is relatively difficult for me to use English to express my ideas. Even if my concept is correct it is sad that it becomes a different concept because of my way of presenting it in English." (25A, BM, YR2)

"Grammar I think. Sometimes, I know I make many grammar mistakes, but I cannot rectify them." (33A, SS, YR1)

\subsection{Transition from Deficit to Capital}

English competence is a portmanteau concept acting as a bridge from deficit to capital. In the previous parts of this paper, we discussed that college TSs have identified aspects of English competence as their TD, and described aspects of English competence as TC. This section describes a generic TC, students' eagerness, and helping to transform some English-related TD to TC.

\subsubsection{Realization of Academic Needs}

Due to students' academic experiences in their community-college programs, they see the need to improve their English for better academic performance. While their academic experience itself is not English-related, it helps them see the need to do better, including the need to write better in English and to communicate with other students during class.

"The standard of requirements in writing (in degree studies) is much higher than in the community college. Apart from writing with excellence, we are also required to be attentive to details. Therefore, the motivation for you to write in better English is now an academic need." (16B, LRS, YR2)

"The (learning) environment is now in English, with assignments in English. When studying in the Higher Diploma, even though the materials were in English, we were using Chinese to express ourselves most of the time. Sometime during the lecture, we were using Chinese to express ourselves. Now that the environment has become English, this basically makes me self-motivated to learn it." (06B, CSIT, YR1)

"I have learnt a lot of different things since I was admitted to the university, including meeting exchange students. I could not adapt to this at first because I graduated from a Chinese-medium secondary school. All of a sudden, we needed some time to adapt to the classes all being in English. I have then started to learn English, and even to apply for some extra English courses for improvement." (40B, ADPA, YR1)

\subsubsection{Realization of Interactional Needs for Communication after Class}

The students also know that they are given more opportunities to interact with nonlocal students and teachers now, in university, than in their community college studies. English has now become a common language for Chinese and non-Chinese.

"Since there are more overseas students at the university, I will need to use English more frequently communication in English." (10A, S, YR1) 
"In my course, there are more students coming from different places, such as Russia, Kazakhstan, Taiwan, and Mainland China. In this circumstance, you will discover the motivation to learn English." (06C, CSIT, YR1)

"I have changed my motivation after getting into university ... I went to an international summer school during my Year 2 studies. The students came from 26 countries and they were all foreigners. I had a goal to perform better and I volunteered to be a helper to take care of these exchange students ... They gave me lots of opportunities to practise in English, or I would say the environment is international. In every course I studied, I met different exchange students, and I could also meet lots of exchange students in the hostel." (20B, ADPA, YR2)

\subsubsection{Realization of Needs via Peer Competition}

Some college TSs said they might compare themselves with students who were admitted directly to university. Due to their academic experiences, they knew that they were not as good as others and this became a motivation for them to improve their English proficiency.

"And most likely it is necessary to learn English. Otherwise, my English proficiency in aspects such as reading, writing, and communication is far below the standard when compared with other students." (10A, S, YR1)

"Also, the main-stream students' English is highly proficient, and this is my motivation to improve." (04B, SN, YR2, female)

"When I was admitted to the university, I found people around me had higher levels of English proficiency ... I feel competitive and I have started to make more effort to learn English." (25A, BM, YR4, female)

\section{Discussion}

This study is probably the first of its kind to unpack the idea of English competence as TC and TD for ESL TSs in an Asian higher education context. According to our qualitative results, the students regarded their English proficiency, developed in their community colleges, to consist of basic academic skills and general academic writing skills, which are TC. On the other hand, listening and speaking in non-academic contexts, and reading and writing skills in advanced research writing are considered as TD. The results also showed that, with the realization of academic needs, interactional needs for communication after class, and needs via peer competition, the students were motivated by their community college experiences to improve their English and their experience of doing so helped to transit their English problems from deficit to capital.

\subsection{Transfer Capital}

\subsubsection{Basic Academic Skills Strategies}

The results demonstrated that community colleges have prepared students' English proficiency, enabling them to attend classes and to handle assignments as basic academic skills strategies. Past studies have reported that ESL students "lack effective academic skills", such as handling assignments and taking notes in classes (p.67) [34]. This perception might have changed with the perfection of the curriculum. This research recognizes the importance of community college nowadays to have laid a solid foundation for students to adapt university studies for further academic strategies to be developed as TC.

\subsubsection{General Academic Writing Strategies}

Most students in our study reported general academic writing strategies they had learned as TC. The strategies learned included general academic writing strategies, such as developing a paper in accordance with the macro structure of academic discourse (e.g., general organizational patterns of a paper and what moves are included in an introduction), incorporating sources to strengthen arguments, and writing with the register of academic 
communication. These writing strategies are important to university studies and it has been shown that tertiary students can learn them effectively [35]. More importantly, these skills can be developed for students at different levels of English proficiency. A student with a relatively weaker English foundation can do citations properly and avoid academic style issues, just as those with higher levels of proficiency can do. This echoes Pullen's [22] suggestion that TSs can benefit from source-based writing training, even if transfer shock is not the main focus. Despite their problems with language use, the strategies the students had developed can cater to general university needs and their academic writing needs, at least to a certain extent.

The importance of recognizing general academic writing skills as TC is about not only appreciating their ability but also being specific with their English needs. Some past studies did not recognize these aspects of English competence as TC, and simply recommended that students take more English courses [25].

\subsection{Transfer Deficits}

\subsubsection{Listening and Speaking}

ESL TSs may have experienced difficulties with listening and speaking in non-academic contexts. The English admission requirement for community colleges (Level 2 in university entrance examination) is lower than for degree programs (Level 3 in university entrance examination) [36]. In reality, some authors [37] conducted a comparative study of undergraduate TSs in Hong Kong. It was estimated that 34.0\% of TSs obtained Level 2, 46.3\% obtained Level 3, and 16.3\% obtained Level 4. However, the authors of [38] reported that $66.4 \%$ of all undergraduates (across three cohorts) had attained Level 4 and 33.6\% had Level 3, in a comparable research site. With a comparable research site across these studies and the current study, it is possible to claim that the majority of TSs have lower public exam results with a relatively weaker language foundation.

When they enter community college programs, students may not be confident enough about their English skills and it is possible that some of their teachers will use Chinese, their mother tongue, to teach. It is not uncommon in the Hong Kong tertiary education context that, even when the formal medium of instruction is English, some teachers may not observe this policy due to the students' lack of language proficiency [39]. With most of their instruction being related to their discipline subjects, TSs might only take one or two English courses each semester to enhance their EAP skills (which may be similar to their counterparts, with better proficiency, who entered undergraduate programs). Most of these EAP skills are those described above as TC, and there may not be sufficient focus on language proficiency. Flowerdew and Peacock [40] suggested that it is difficult to teach all skills needed for tertiary study when only limited EAP courses are provided. Given that they might only experience limited English usage in their learning environments, it is not surprising that students may find it difficult to communicate outside the classroom in non-academic contexts (which is only a matter of language proficiency, not EAP skills), and another compounding factor could be the variations of accents they experience. Therefore, it is possible that general language proficiency seems to be a TD, as the college TSs in this study said they were admitted to university with weak language proficiency and insufficient proficiency-based training from their sub-degree studies.

\subsubsection{Reading and Writing Skills}

A further challenge for the ESL TSs interviewed in this study was the need for reading and writing skills appropriate for advanced research writing genres. This, in fact, echoes Geide-Stevenson's [41] report that international-although non-transfer-students' weaker language foundations had negative impacts on their capstone projects, even despite the success of their initial ESL programs. While ESL TSs seem to have weaker language foundations, which can explain their reading skills as a TD, their weaker foundation prevents them from writing advanced genres that demand high grammar accuracy, and the use of a wide range of vocabulary. Therefore, it is no surprise for writing skills to be TD. 
It is possible that TSs may not be required to read many academic texts extensively during their community college studies. Students completing their community college coursework may only be required to complete designated course readings when preparing for classes. Schnee [42] reported that $70 \%$ of faculty-assigned readings are from textbooks and this is the most popular type of reading, followed by PowerPoint slides. Schnee [42] also revealed that more than half of faculty members assigned reading-based essays to assess whether their students completed the assigned readings. According to a report from the National Center on Education and the Economy (NCEE) in 2013 [43], most of these assignments were just simple "information retrieval". Under such circumstances, students may not find reading textbooks (as compared with authentic journal articles/book chapters) too challenging when they encounter them in their degree programs. With insufficient strategies and limited practice in reading journals and writing with research-based practice, college TSs experience problems in reading and writing evidence-based research papers as TD.

\subsection{Transforming Deficits to Capitals}

It is pleasing to note that, due to their community college experiences, the students found the need to improve their English for various reasons. As discussed in the Results section, they could see the gap between university and community college education, and realize their own TDs: they had not received sufficient proficiency-based training for academic, professional, and interactional purposes and they also had the problem of having used Chinese as their medium of instruction prior to entering university, so they could understand why it is difficult to adjust to the EMI university education. In practice, they knew from their sub-degree experience that it was important to have good English skills, but it was only when they entered university that they saw the need for these skills and became motivated to improve. Such motivation transforms certain English-related TD to TC.

As mentioned earlier, TSs may not have sufficient opportunities to read academic journals and write research papers in their sub-degree programs. When they transfer to university, their assignments are more "research or professionally oriented" [44]. These usually require more research and reading skills. Facing these "advanced" problems together with the goal to remain competitive with the degree students motivated them to improve their English. As a result, this can be considered as a transformation from deficits to capital.

\subsection{Limitations}

Some respondents may have felt uncomfortable to discuss their academic performances with the presence of other students, since this is relatively personal. However, since the focus of our research was on their English learning, the relevance and accuracy of our findings should not have been affected. Another possible limitation is that seven of the interviews were conducted individually. This might have caused the exchange of ideas to be less interactive and dynamic. Nevertheless, these individual interviews were justified by the nature of the research and interview questions, and in fact around $94 \%$ of the respondents participated in focus group interviews. The use of qualitative methods may have been another limitation. The researchers adopted an interpretivist view in this study and were interested in the multiple realities faced by TSs. However, if the researchers had adopted a post-positivist view, there would be a need to conduct questionnaires in the future to gauge a general view of students' transfer capital and deficits.

\section{Conclusions and Implications}

This study has provided specific details about English competence as TD (or potential capital) during the transfer process, instead of naming it as a problem, as was the case in previous studies. In particular, this research identified a range of approaches, such as basic academic strategies and general academic writing strategies, as TC for TSs. Listening and 
speaking in non-academic contexts, and reading and writing in evidence-based research papers were identified as TD. Students' eagerness and motivation to improve their English skills can potentially be transformed from TD to TC. Whether a factor is categorized as a TD or TC can be explained on the basis of the current teaching and learning practices in the community-college programs and how they shape students' language-learning journeys. Further, considering both TC and TD reminds educators not only to address the TD faced by TSs, but also to acknowledge their TC when designing support measures. Educators are well advised to pay attention to the following specific implications:

1. TSs should take additional proficiency-based courses, on top of EAP courses. These proficiency-based courses should help students to develop basic English abilities, such as listening, writing, speaking, and reading.

2. To maintain TSs' interest, support measures, other than those that are necessarily proficiency-based, should no longer focus on general academic writing skills (e.g., essay-writing skills, or referencing skills) but instead on advanced research writing genres, such as skills for writing a capstone project and strategies for reading academic articles.

3. Support with advanced research writing genres such as capstone projects should be provided for students who are new to a discipline. This should build onto their existing vocabulary acquisition skills and introduce them to some common disciplinespecific vocabulary so that they can enhance their skills to read research articles.

When designing support measures, educators should be aware of students' transfer capital and deficits, as described above. In arriving at this conclusion, it is essential that support measures are aimed at turning deficit into capital. Future studies should evaluate the effectiveness of such support measures to provide evidence-based practices.

Author Contributions: Conceptualization, D.F.; methodology, D.F.; validation, K.C.; formal analysis, D.F. and K.C.; investigation, D.F.; resources, K.C.; data curation, K.C.; writing-original draft preparation, D.F.; writing - review and editing, K.C.; project administration, K.C.; and funding acquisition, K.C. and D.F. All authors have read and agreed to the published version of the manuscript.

Funding: This research was funded by the University Grant Committee (UGC) Funding Scheme for Teaching and Learning Related Proposals (2016-2019 Triennium) (PolyU6/T\&L/16-19) and the Teaching Development and Language Enhancement Grant for Language Enhancement Activities (2016-2019 Triennium) from The Hong Kong Polytechnic University (ELC04).

Institutional Review Board Statement: The study was conducted according to the guidelines of the Declaration of Helsinki, and approved by the Ethics Committee of The Hong Kong Polytechnic University (HSEARS20170808003 on 08 August 2017).

Informed Consent Statement: Informed consent was obtained from all subjects involved in the study.

Data Availability Statement: The data presented in this study are available on reasonable request from the corresponding author.

Acknowledgments: The authors are grateful to all the college transfer students for their participation in the study and the funding provided by the University Grant Committee (UGC) Funding Scheme for Teaching and Learning Related Proposals (2016-2019 Triennium) (PolyU6/T\&L/16-19) and the Teaching Development and Language Enhancement Grant for Language Enhancement Activities (2016-2019 Triennium) from The Hong Kong Polytechnic University (ELC04). We would also like to thank Guan, Yuanyuan, Zhang Lillian Weiwei, Wong, Manyi, Ceci S.W. Ho, and student assistants for their help.

Conflicts of Interest: The authors declare no conflict of interest.

\section{References}

1. Monaghan, D.B.; Attewell, P. The Community College Route to the Bachelor's Degree. Edu. Eval. Policy Anal. 2015, 37, 70-91. [CrossRef]

2. Acai, A.; Newton, G. A comparison of factors related to university students' learning: College-transfer and direct-entry from high school students. Can. J. High. Edu. 2015, 45, 168-192. [CrossRef] 
3. Cheung, K.; Chan, E.S.W.; Ng, J.; Tsang, H.; Leong, H. Comparison of workload and academic performances of transfer and native students in an Asian educational context. High. Educ. Res. Dev. 2020. [CrossRef]

4. $\quad$ Cheung, K.; Tsz, L.Y.; Wan, C.L.J.; Tsang, H.; Lillian, W.Z.; Parpala, A. Differences in study workload stress and its associated factors between transfer students and freshmen entrants in an Asian higher education context. PLoS ONE 2020, 15. [CrossRef] [PubMed]

5. Heung, K.; Ng, J.; Tsang, K.; Pang, K.; Wan, J.; Moser, K. Factors affecting direct and transfer entrants' active coping and satisfaction with the university. Int. J. Environ. Res. Public Health 2020, 17, 2803. [CrossRef]

6. Wong, Y.L. Angels falling from grace? The rectification experiences of middle-class community-college students in Hong Kong Stud. High. Edu. 2019, 44, 1303-1315. [CrossRef]

7. Jain, D.; Melendez, S.N.B.; Herrera, A.R. Power to the Transfer: Critical Race Theory and a Transfer Receptive Culture; MSU Press: East Lansing, MI, USA, 2020.

8. Hills, J.R. Transfer Shock. J. Exp. Edu. 1965, 33, 201-215. [CrossRef]

9. McCormick, A.C.; Sarraf, S.A.; BrckaLorenz, A.; Haywood, A. Examining the Transfer Student Experience: Interactions with Faculty, Campus Relationships, and Overall Satisfaction. In Proceedings of the Association for the Study of Higher Education, Vancouver, BC, Canada, 4-7 November 2009.

10. Laanan, F.S.; Starobin, S.S.; Eggleston, L.E. Adjustment of community college students at a four-year university: Role and relevance of transfer student capital for student retention. J. College Stud. Retent. Res. Theor. Pract. 2010, 12, 175-209. [CrossRef]

11. Committee on Self-Financing Post-Secondary Education. Key Statistics on Post-Secondary Education. 2020. Available online: https://www.cspe.edu.hk/resources/pdf/en/postsec_keystat.pdf (accessed on 2 October 2021).

12. Committee on Self-Financing Post-Secondary Education. Graduate Statistics. 2020. Available online: https://www.cspe.edu.hk/ en/customised-data-retrieval.page (accessed on 2 October 2021).

13. Kember, D.; Ho, A.; Hong, C. Initial motivational orientation of students enrolling in undergraduate degrees. Stud. High. Edu. 2010, 35, 263-276. [CrossRef]

14. Howells, V.; Zelnik, T. Making art: A qualitative study of personal and group transformation in a community arts studio. Psychiatr Rehabil. J. 2009, 32, 215-222. [CrossRef]

15. Smith, A.; Sturtevant, K.; Bullough, E. Transfer Students: Retention and Persistence; Utah Valley University: Orem, UT, USA, 2021.

16. Utter, M.; DeAngelo, L. Lateral transfer students: The role of housing in social integration and transition. J. College Univ. Stud. Hous. 2015, 42, 178-193.

17. Robison, M.; Fawley, N.; Marshall, A. "That background knowledge": What junior and senior undergraduate transfer students need from their libraries. J. Acad. Librariansh. 2019, 46, 102092. [CrossRef]

18. Cameron, C. Experiences of transfer students in a collaborative baccalaureate nursing program. Community College Rev. 2005, 33, 22-44. [CrossRef]

19. Martirosyan, N.M.; Hwang, E.; Wanjohi, R. Impact of English proficiency on academic performance of international students. J. Int. Stud. 2015, 5, 60-71. [CrossRef]

20. Nasirudeen, A.M.A.; Xiao, S. English language skills and academic performance: A comparison between Asian international and domestic nursing students in Singapore. Int. J. Nurs. 2020, 7, 30-38. [CrossRef]

21. Liu, J.; Pascarella, E.T. Does language background have an effect on the development of psychological well-being during college? J. College Stud. Dev. 2020, 61, 648-653. [CrossRef]

22. Pullen, T. Writing Center Use Among Transfer Students. Master's Thesis, Western Illinois University, Macomb, IL, USA, 2019. Available online: http://www.wiu.edu/cas/english/graduate/thesis_projects.php (accessed on 2 October 2021).

23. Frodesen, J. Beyond First-Year Composition: Academic English Instructional Support for International Transfer Students. CATESOL J. 2015, 27, 33-54.

24. Castro, E.; Cortez, E. Exploring the lived experiences and intersectionalities of Mexican community college transfer students: Qualitative insights toward expanding a transfer receptive culture. Community College J. Res. Pract. 2017, 41, 77-92. [CrossRef]

25. Schwehm, J.S. Do student demographics and community college experiences influence the adjustment process of adult vertical transfer students? Community College Enterp. 2017, 23, 9-25.

26. Ching, S.S.Y.; Tam, K.Y.; Zhang, L.W.W.; Ng, J.; Cheung, K. A qualitative exploration on the challenges of transfer students in an Asian educational context. Int. J. Environ. Res. Public Health 2021, 18, 3238. [CrossRef]

27. Cyr, J. The Pitfalls and Promise of Focus Groups as a Data Collection Method. Sociol. Methods Res. 2015, 45, 231-259. [CrossRef]

28. Graneheim, U.H.; Lundman, B. Qualitative content analysis in nursing research: Concepts, procedures and measures to achieve trustworthiness. Nurse Educ. Today 2004, 24, 105-112. [CrossRef] [PubMed]

29. Graneheim, U.H.; Lindgren, B.M.; Lundman, B. Methodological challenges in qualitative content analysis: A discussion paper. Nurse Educ. Today 2017, 56, 29-34. [CrossRef]

30. Morgan, D.L. Focus Groups as Qualitative Research; Sage: Thousand Oaks, CA, USA, 1996; Volume 16.

31. Morse, J.M. Critical Issues in Qualitative Research Methods; Sage: Thousand Oaks, CA, USA, 1994.

32. Basch, C.E. Focus group interview: An underutilized research technique for improving theory and practice in health education. Health Educ. Q. 1987, 14, 411-448. [CrossRef] [PubMed]

33. McLafferty, I. Focus group interviews as a data collecting strategy. J. Adv. Nurs. 2004, 48, 187-194. [CrossRef]

34. Adamson, H.D. ESL students' use of academic skills in content courses. Engl. Specif. Purp. 1990, 9, 67-87. [CrossRef] 
35. Lughmani, D.S.; Foung, D. Metacognitive strategy-focused instruction in a writing across the curriculum programme in a Hong Kong university: The impact on writing performance. In Innovative Approaches in Teaching English Writing to Chinese Speakers; Reynolds, B.L., Teng, M.F., Eds.; De Gruyter Mouton: Berlin, Germany, 2021; pp. 145-178. [CrossRef]

36. Hong Kong Examinations and Assessment Authority. International English Language Testing System (IELTS); HKEAA: Tuen Mun, Hong Kong, 2012; Available online: https://www.hkeaa.edu.hk/en/recognition/benchmarking/hkdse/ielts/ (accessed on 21 October 2021).

37. Foung, D.; Cheung, K.; Chen, J.; Lin, L. Exploring the language needs of college transfer students in Asia. Presented at the Lilly-Asia Conference on Evidence-Based Teaching and Learning, Kowloon, Hong Kong, 16-18 May 2019.

38. Foung, D.; Chen, J. A Learning Analytics Approach to the Evaluation of an Online Learning Package in a Hong Kong University. EJE 2019, 17, 11-24.

39. Li, N.; Leung, D.Y.; Kember, D. Medium of instruction in Hong Kong universities: The mis-match between espoused theory and theory in use. High. Educ. Policy 2001, 14, 293-312. [CrossRef]

40. Flowerdew, J.; Peacock, M. (Eds.) Issues in EAP: A Preliminary Perspective. In Research Perspectives on English for Academic Purposes; Cambridge University Press: Cambridge, UK, 2001; pp. 8-24.

41. Geide-Stevenson, D. Does English proficiency affect academic performance? Int. Rev. Econom. Educ. 2018, 28, 41-48. [CrossRef]

42. Schnee, E. Reading across the curriculum at an urban community college: Student and faculty perspectives on reading. Community College J. Res. Pract. 2018, 42, 825-847. [CrossRef]

43. National Center on Education and the Economy (NCEE). What Does It Really Mean to Be College and Work Ready? The English Literacy Required of Community College Students; NCEE: Washington, DC, USA, 2013; Available online: http:/ / ncee.org/collegeand-work-ready/ (accessed on 21 October 2021).

44. Gardner, S.; Nesi, H.; Biber, D. Discipline, level, genre: Integrating situational perspectives in a new MD analysis of university student writing. Appl. Linguist. 2018, 40, 646-674. [CrossRef] 